\title{
FUNCTIONING OF CATFISH ELECTRORECEPTORS: BURSTING DISCHARGE PATTERN OF KRYPTOPTERUS ELECTRORECEPTORS ELICITED BY MICROELECTRODE IMPALEMENT
}

\author{
A. M. J. VAN DONGEN and F. BRETSCHNEIDER \\ Laboratory of Comparative Physiology, State University of Utrecht, Jan van Galenstraat 40, 3572 LA, \\ Utrecht, The Netherlands. Telephone: 030-716221
}

(Received 5 July 1983)

\begin{abstract}
The time course of the spontaneous discharge of Kryptopterus ampullary electroreceptors may change from regular to bursting upon impalement by a glass microelectrode.

2. The burst duration is very constant relative to the interburst interval, during spontaneous fluctuations as well as in response to low-frequency stimulation.

3. Implications for the current model of the functioning of catfish electroreceptors are discussed.
\end{abstract}

\section{INTRODUCTION}

The electroreceptors of the transparent catfish Kryptopterus bicirrhis are of the ampullary type (Wachtel and Szanier, 1969) and are sensitive to low-frequency electric currents (Bennett, 1971; Roth, 1973, 1978). Although the course of the transmission from electric current in the water to afferent nerve impulses is not yet fully understood, the following processes are likely to occur when a receptor is stimulated by an anodal, i.e. inward current. The stimulus current flows through the apical membranes of the receptor cells. which results in a slight depolarization of the intracellular potential. This depolarization (probably) causes an inflow of calcium ions which, in turn, enhance the release of an exciting transmitter substance. The postsynaptic membrane is depolarized by the increased transmitter flux, which results in a higher impulse rate at the spike generation site (Bennett and Clusin, 1979; Teeter and Bennett, 1981).

Due to stray fields, the impulses can be recorded from the lumen of the receptors, as well as from the receptor cells (Bennett, 1971). The former method, being non-invasive, ensures undisturbed functioning of the receptor, whereas the latter permits measurement of the membrane potential of the receptor cells. Contrary to the situation in other types of electroreceptors, the apical membranes of ampullary electroreceptors of freshwater catfish appear to be electrically non-excitable (the reader is referred to Bennett and Clusin, 1979, for a full discussion of this subject).

However, following impalement of a sensory cell with a glass microelectrode (Fig. 1) the nerve activity often changes from fairly regular firing into a conspicuous bursting discharge pattern. This usually lasts for a few minutes, after which the regular discharge pattern is re-established. The occurrence of bursts can usually be prevented by the use of relatively high-impedance micropipettes $(30-50 \mathrm{M} \Omega)$ and by very careful electrode insertion using a highmagnification microscope. Nevertheless, we decided for a further examination of the bursting discharge pattern for the following reasons.

First, the easy to obtain and reproducible sudden change to a bursting discharge pattern is not to be expected in sensory organs, their main function being reliable and continuous transduction of external information into a frequency-coded nerve signal.

Secondly, understanding the bursting mechanism might give clues about normal receptor functioning. Besides recording and analysing the bursting pattern, we tried to influence bursting electroreceptors by electrical stimulation. Implications of the results for the current model of the functioning of catfish electroreceptors are discussed.

\section{MATERIALS AND METHODS}

Transparent catfish (Kryptopterus bicirrhis), about $4 \mathrm{~cm}$ long, were placed in a shallow dish, filled with recirculating aerated water of $25 \pm 1 \mathrm{C}$ after immobilization with Flaxédil (gallamine; Specia, Paris). The same water was supplied to the fish through a polythene cannula into the oral cavity. The dish was mounted on the stage of a microscope fitted with water immersion objective lenses, allowing observation of the electroreceptors with a high magnification, using transmitted light. The immobilization of the fish usually lasted for about $3 \mathrm{hr}$, after which the fish were returned to the stock tank.

We used glass micropipette recording electrodes filled with $3.0 \mathrm{M} \mathrm{KCl}$ (impedance 5-20 M $\Omega$ ). For impalement, the microelectrode was manoeuvred through the porus of the receptor in such a way that a receptor cell could be penetrated by a slight, axial movement of the manipulator. A reference electrode having a larger tip diameter and filled with $0.1 \mathrm{M} \mathrm{KCl}$ was placed in the water near the fish. The differential signal was amplified (bandwidth d.c. $-3 \mathrm{kIIz}$ ) and stored on magnetic tape.

Interspike intervals were measured with an electronic counter and fed into a microcomputer. As the interburst intervals were substantially longer than any interspike interval within a burst, the spike train was analysed by segregating intervals into two classes. Thereafter, the burst duration, the mean frequency during a burst (the number of spikes in a burst divided by the burst duration) and the 


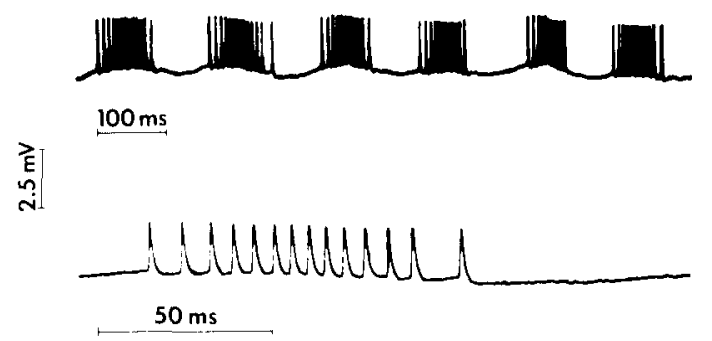

Fig. 1. Example of a bursting spike brain from an electroreceptor. Upper trace: six consecutive bursts on a time scale that precludes resolution of all individual spikes in a burst.

Lower trace: one burst on a faster time scale.

"period" (sum of burst duration and the next interburst interval) were calculated. These parameters were plotted as a function of the burst number, together with the interburst interval.

To investigate the role of the synapses in the bursting mechanism, both bursting and normal functioning electroreceptors were stimulated electrically. Stimulus current was applied by a fork-shaped silver wire, placed near the recording electrode. The effects of a low frequency $(0.3 \mathrm{~Hz})$ sinusoidal stimulus current and of anodal and cathodal direct current on the above-mentioned parameters were observed. The influence of a strong cathodal current on the sensitivity of the normal functioning (non-bursting) electro- receptor was investigated by superimposing an alternating current $(5 \mathrm{~Hz})$ on the d.c.-steps, while recording from the lumen (cf. Bretschneider et al,, 1980, for the effects of cathodal current on electroreceptors of Ictalurus nebulosus).

\section{RESULTS}

\section{Burst characterization}

Upon penetration, the potential measured by the microelectrode usually jumped to between -20 and $-30 \mathrm{mV}$, followed by a slow decrease to a value between zero and $-10 \mathrm{mV}$. Bursting usually followed impalement within a few seconds. In all, 41 receptors (of 11 fish) were impaled, followed by bursting in 36 cases. In most cases, bursting lasted for several minutes, allowing characterization of both the spontaneous behaviour and the response to electrical stimulation. An example of the spontaneous bursting pattern is shown in Fig. 1. Figure 2 shows the time course of the variables burst duration, interburst interval, period and mean spike frequency in a burst for a series of 130 consecutive bursts (ca. $25 \mathrm{sec}$ ). Although the burst duration varied from 40 to $90 \mathrm{msec}$ between experiments, the burst duration within a series is fairly constant, whereas the interburst interval is not. It should be mentioned, however, that a few deviating bursts occurred in the transitions from continuous firing to bursting and
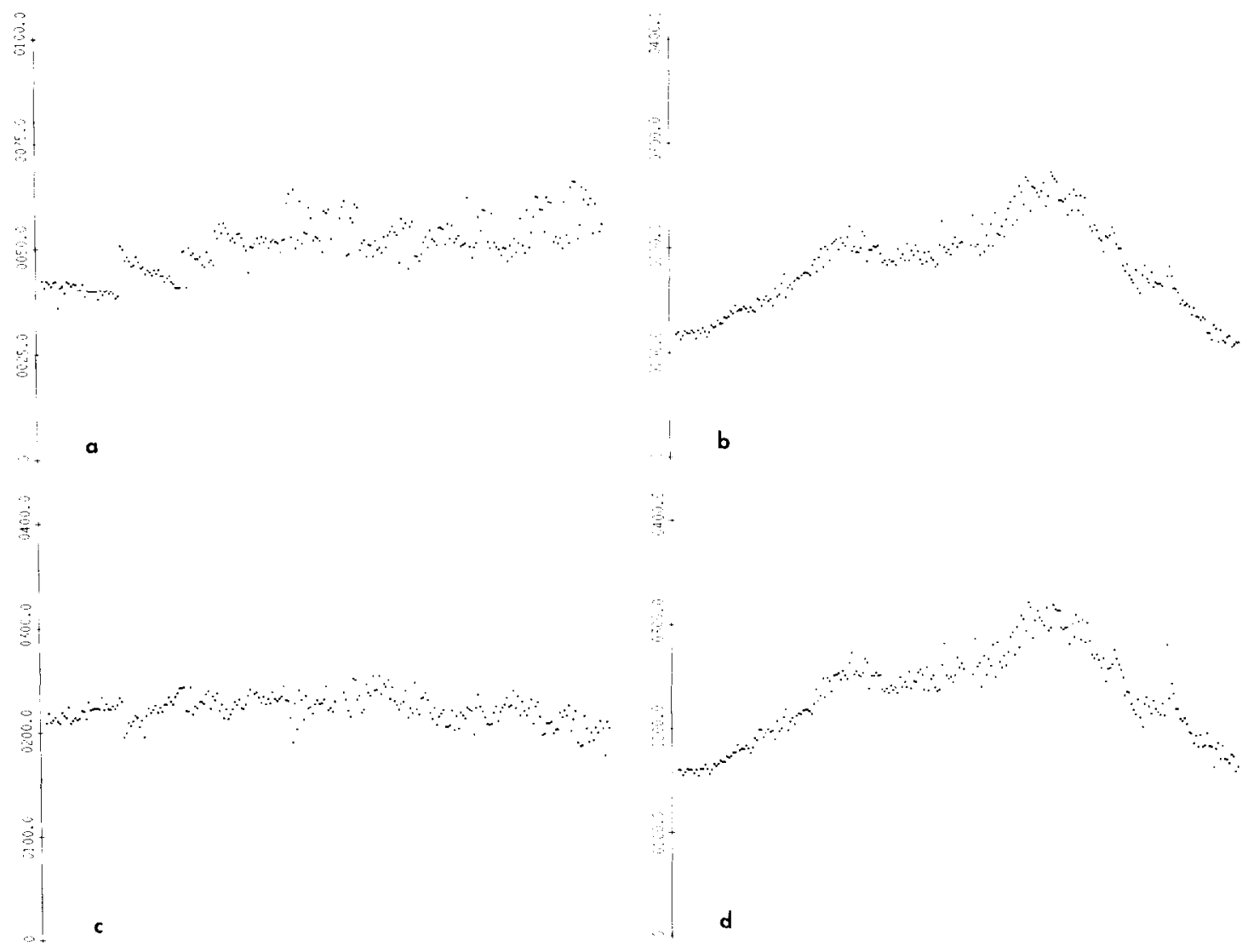

Fig. 2. Example of spontaneous variation of the variables (a) burst duration, (b) interburst interval, (c) mean spike frequency in burst, and (d) burst period. Horizontal axis: serial number of burst: vertical axis: time in msec in (a), (b) and (d) frequency in spikes/sec in (c). 


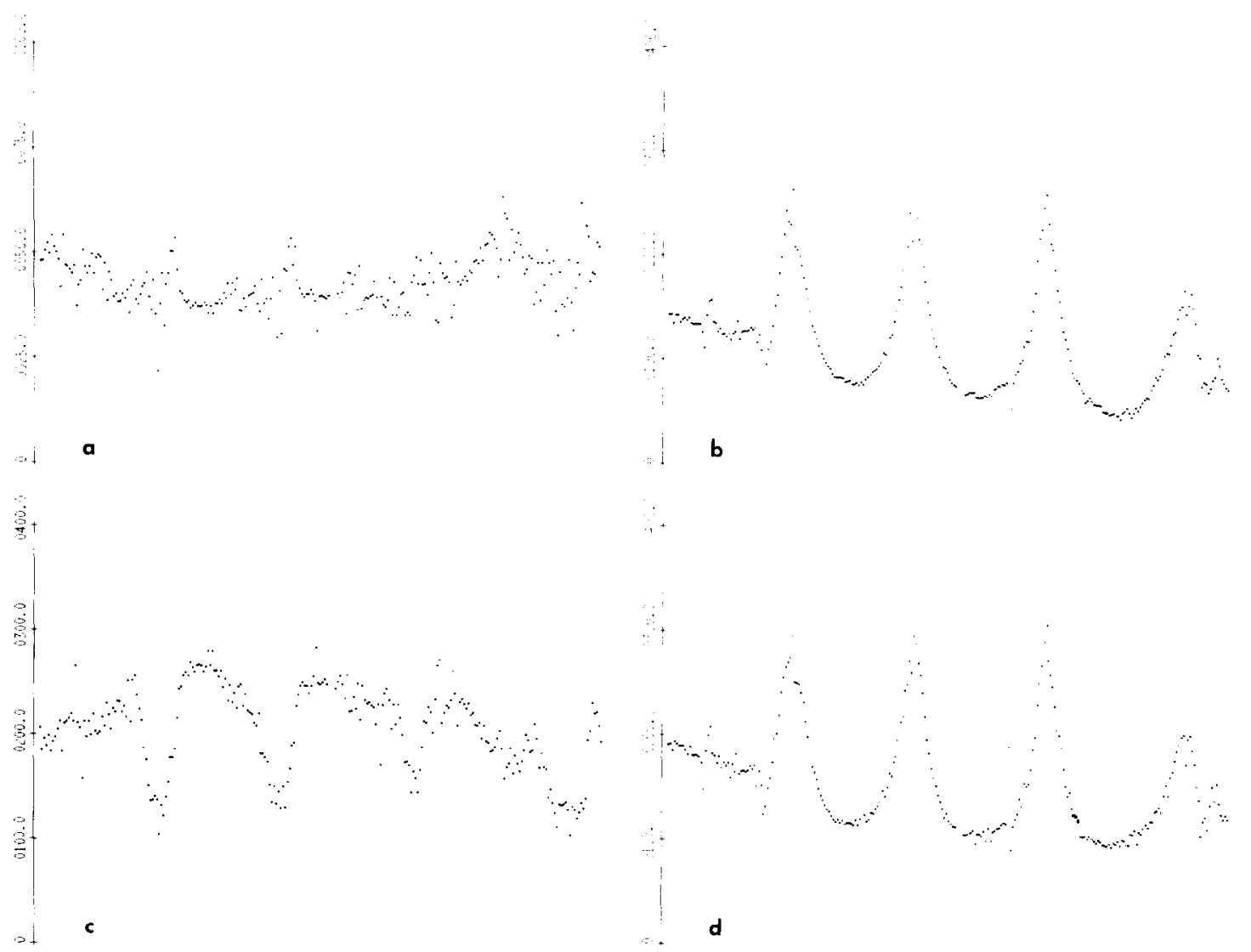

Fig. 3. Example of modulation of burst variables by a $0.3 \mathrm{~Hz}$ sinusoidal stimulus current. Meaning of letters (a)-(d) and calibration of axes as in Fig. 2.

vice versa. These are not included in the figures. Not depicted is the number of spikes per burst, which varied between 7 and 15 between experiments. In Fig. 2, discontinuities in burst duration and mean spike frequency in burst can be seen at each addition of one spike per burst.

\section{Low-frequency stimulation}

When an electroreceptor is stimulated with a sinusoidal current $\left(0.3 \mathrm{~Hz}, 100 \mathrm{nA} / \mathrm{cm}^{2}\right)$ during bursting, the difference in variation between the burst duration and the interburst interval becomes even more pronounced. The low-frequency current "modulates" the burst parameters. The modulation of the interburst interval is larger than the modulation of the burst duration (Fig. 3). The "instantaneous frequency" (reciprocal of interburst interval) responds linearly (i.e. sinusoidally) to the sinusoidal stimulus current.

\section{Direct current stimulation}

The effects of stimulation with direct current on the bursting discharge pattern can be described as follows. The influence of relatively weak $\left(<250 \mathrm{nA} / \mathrm{cm}^{2}\right)$ anodal and cathodal d.c.-steps was small: after an initial increase or decrease of the firing frequency, the original bursting discharge pattern was re-established in a few seconds. Stimulation with a strong anodal (exciting) direct current $\left(250-500 \mathrm{nA} / \mathrm{cm}^{2}\right)$ changed the discharge pattern into regular high-frequency firing. In most cases the bursting pattern reappeared within one minute. The bursting responded different to a strong cathodal (inhibiting) direct current. After an initial silent period of a few seconds, bursting reappeared with a longer period. In a few minutes the burst frequency returned to the normal (unstimulated) level.

Normal, i.e. non-impaled, electroreceptors responded to a cathodal current step in the same way as electroreceptors of Ictalurus (Bretschneider et al., 1980): the spike rate is zero for a few seconds, after which a low, regular spike rate is established. During this period, the receptor is insensitive for an added alternating current. Normal spike rate and a.c.-sensitivity return slowly in about $10 \mathrm{~min}$.

\section{DISCUSSION}

The results can be summarized as follows: upon impalement of a receptor cell with a glass microelectrode, the normally regular spike train often starts bursting. The duration of the bursts is rather constant; about $60 \mathrm{msec}$. The interburst intervals are, on the contrary, of variable duration, showing both spontaneous variation and response to electrical stimulation.

The oscillatory membrane potential excursions that presumably underlie the intermittent spike gen- 
eration may arise in either pre- or postsynaptical parts of the receptor. If the time course of the spike rate is taken as an approximate measure of the hypothetical membrane potential variation, the burst cycle resembles a slow action potential. Sinilar, slow action potentials, often caused by a calcium influx mechanism and called calcium spikes for short, have been found elsewhere, e.g. in the ampullary electroreceptors of skates. In this receptor type, the spikelike oscillations are found at the apical membranes of the receptor cells, and can be recorded from the lumen of the ampullae (Obara and Bennett, 1972). This electrical excitability is thought to be an explanation of the high electrosensitivity of skate electroreceptors (cf. Bennett and Clusin, 1979). The mode of operation of catfish electroreceptors is, however, thought to be different. Intracellular measurements have shown, so far, only absence of electrical excitability of the apical membrane. This was stated by Bennett (1971) and confirmed by our own measurements. Added to the observation of post-synaptic potentials of normal, i.e. large size in the marine catfish Plotosus, this leaves the synapses of catfish electroreceptors as the most electrosensitive component in the transduction chain (Bennett and Clusin, 1979).

Although bursting in Kryptopterus receptors is initiated by impalement of a receptor cell, we do not expect the oscillation to arise presynaptically for the following reasons. In the first place, no voltage excursions large enough to be responsible for the observed, vigorous spike frequency modulation, are recorded by the intracellular electrode that initiated the bursting. Secondly, the bursting could not be suppressed by a negative current of several microampere, whereas such a current does abolish the normal functioning of intact receptors. The presynaptical disturbance that starts the bursting might be a depolarization caused by electrode leakage. This might be indicated by the rather low intracellular potentials we found. Such low membrane potentials have been found in several types of small, cultured cells and have been ascribed to a leakage resistance formed by the hydration mantle of the glass micropipette (Lassen et al., 1971; Ince et al., 1983). The surface area of the receptor cells of Kryptopterus electroreceptors is of the same order of magnitude (ca. $500 \mu \mathrm{m}^{2}$ ).

If the bursting can be evoked by a depolarization of only one of the 20-25 receptor cells of a Kryptopterus electroreceptor, the postsynaptic potential has to be rather close to an instability. This suggests then, that besides the synaptical transduction, the electrical properties of the postsynaptic membranes are a factor enhancing the overall electrical sensitivity of catfish electroreceptors.

\section{REFERENCES}

Bennett M. V. L. (1971) Electrolocation in fish. Ann. N.Y. Acad. Sci. 188, 242-269.

Bennett M. V. L. and Clusin W. T. (1979) Transduction at electroreceptors: origins of sensitivity. In Membrane Transduction Mechanisms (Cone R. A. and Dowling J. E., eds), pp. 91 121. Raven Press, New York.

Bretschneider F., Peters R. C., Peele P. H. and Dorresteijn A. (1980) Functioning of catfish electroreceptors: distribution of sensitivity and fluctuations of spontaneous activity. J. comp. Pysiol. 137, 273-279.

Ince C., Ypey D. L., Furth R. van and Verveen A. A. (1983) Estimation of the membrane potential of cultural macrophages from the fast potential transient upon microelectrode entry. J. Cell Biol. 96, 796-801.

Lassen U. V., Nielsen A.-M. T., Pape L. and Simonsen L. O. (1971) The membrane potential of Ehrlich ascites tumor cells. Microelectrode measurements and their critical evaluation. J. Membrane Biol. 6, 269-288.

Obara S. and Bennett M. V. L. (1972) Mode of operation of ampullae of Lorenzini of the skate, Raja. J. gen. Physiol. 60, 534-557.

Roth A. (1973) Ampullary electroreceptors in catfish: afferent fiber activity before and after removal of the sensory cells. J. comp. Physiol. 87, 259-275.

Roth A. (1978) Further indications of a chemical synapse in the electroreceptors of the catfish. J. comp. Physiol. 126, 147-150.

Teeter J. H. and Bennett M. V. L. (1981) Synaptic transmission in the ampullary electroreceptor of the transparent catfish, Kryptopterus. J. comp. Physiol. 142, 371-377.

Wachtel A. W. and Szamier R. B. (1969) Special cutaneous receptor organs of fish: IV Ampullary organs of the non-electric catfish, Kryptopterus. J. Morphol. 128, 291-308. 